\title{
Environmental Auditing of a Packaging System for Redesign: A Case Study Exploration
}

\author{
J. Matthews, C. Parr, O. Araoye, and M. McManus
}

\begin{abstract}
Within the United Kingdom a significant portion of the energy consumed each year is done so through industry. It is therefore desirable to take measures that reduce this consumption. A process common to all manufacturing sectors is that of packaging, and this research focused on identifying, quantifying and reducing the environmental impact of one such system. It finally took the form of an abridged life cycle assessment focusing on the manufacturing and assembly stage of a packaging systems life. Two separate studies were conducted to evaluate the performance of specific tools for such environmental studies. Where, the total embodied energy and carbon of each sub-assembly of the systems was calculated and their contribution to the whole machine established. These were further broken down into material production and machine processes in order to establish where the major impacts were and potential areas for redesign. Both approaches were found to be resource hungry in their application, an output that may restrict their application in the type of company that operate in this domain. A surprising finding was that producing a design with lower environmental impact could be less expensive.
\end{abstract}

Index Terms-Packaging, machine design/ redesign, environmental assessment

\section{INTRODUCTION}

In recent years designers have developed an increased awareness of the environmental impact that their products and systems are having on the world. Industries and businesses are assessing in detail the environmental impact of their activities; production, processing and perception. The response to these assessments has been to try and create "greener" products through more environmentally friendly means [1]. The environmental impact of packaging has become increasing important due the global increase in products being manufactured [2]. Currently there has been a push by supermarkets to ensure that the process of food packaging is as "green" as possible. The initial phase has been the reduction in the volume of packaging employed, light weighting, reduced gauge etc; a secondary phase has been the shift away from conventional packaging to that deemed to be from a "green" source e.g. biopolymers replacing polyefins [3]. The next phase is expected to be the processes of packaging conversion, containment and the system that performs it. To this end the "green" credential of the packaging equipment design needs investigating. This in addition to the fact that machine manufacturers are constantly striving for approaches to develop energy efficient systems thereby providing economic design solutions on quantity of

Manuscript received June 7, 2013; revised July 18, 2013.

Jason Matthews is with the Faculty of Computing, Engineering and Science in the University of Glamorgan. (e-mail: jmatthe1@glam.ac.uk). energy use to their customers. This paper documents the design analysis activities in one such investigation.

A secondary interest within this investigation relates to the companies performing the design assessments. In this instance, the subject company as with many in the machine design and build sector operates as a Small to Medium Enterprises (SME). It employees 19 full time engineers, three technical support staff for management and service and sale and ultilizes a local engineering design company to support its design activities, it supplies its products to the UK and Eire's, Fast Moving Consumer Goods (FMCG) markets. In general being an SME type company there are a few limiting factors effective product development, namely: in general, they lack resources in terms of cash flow, available expertise, management time and adequately trained workforce. Also there is often documentation, a lack of formalized databases, shortened development times and absence of a corporate product structure [4]. With these factors in mind is it is important that the findings of the research leave the subject company with the ability to review, analyze their systems one the research is finished. With the previous factors in mind a number of specific objectives were also developed:

- The first objective was to investigate and identify a range of appropriate tools that can be used to environmentally audit the design of a packaging system.

- The second specific objective, which encompasses the main body of the investigation, is to formulate an environmental audit/ assessment of the packaging machine

- The final objective of the investigation is to evaluate the results of previous stages and produce an effective redesign solution by which the environmental impact could be reduced.

\section{BACKGROUND TO APPROACH AND SUbJeCt AREA}

The environmental performance of products and processes has become a key issue, which is why companies are investigating ways to minimize their affect on the environment. There are a number of tools that can carry out this function, and help improve the environmental performance of products. Major examples being Carbon Foot printing, Environmental Check listing, Material Input per Unit Service (MIPS) and Life Cycle Assessments (LCA)[1]. LCA is a powerful tool for the analysis and optimization of a product over its whole life cycle. When considering the topic of this study, it is particularly useful as it can assist in: identifying opportunities to improve the environmental impacts of products at numerous stages throughout their life: selecting the relevant indicators of 
environmental performance, including measurement techniques and marketing - ecolabelling, environmental claims and environmental product declarations. In order to determine the true environmental impact of a product or system it is necessary to conduct an analysis from the point of its creation until its eventual demise, a "cradle to grave" assessment. LCA is a systematic process for analyzing the environmental impact of products and systems and utilizes four major phases as shown in Fig. 1.

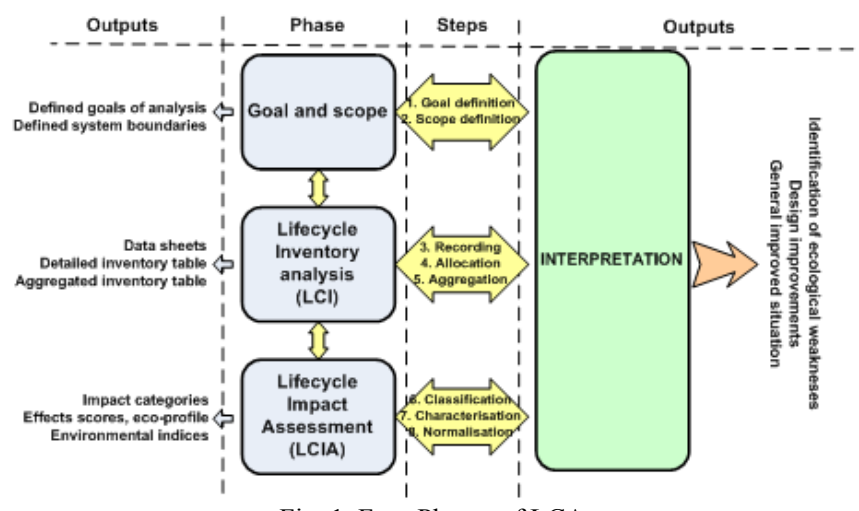

Fig. 1. Four Phases of LCA

The main benefits of LCA are an ability to give an extensive incite into the impacts and emissions of any product or process. Its main strengths are lies in, its ability to assist analysts in producing an evaluation of all the environmental consequences associated with a given product. A comprehensive review of published research into such analysis of packaging was presented by Lee and $\mathrm{Xu}$ [2]; although no reference to the production processes were given. Generic approaches to support the LCA of machine systems have been proposed by Nowosielski et al. [1] and Pramminger et al. [5]. Llandfilda and Karrab [6] investigated the LCA of the rock crushing process. Allen et al. [7] produced an energy analysis and environmental life cycle assessment of micro wind turbines, their study gives an effective example of the use of LCA software in a project. It also shows how analysis of a machine to be broken down into a various subassemblies. The same approach was conducted by Jones and McManus [8] investigating high voltage cables. The green design of subtractive machining has been studied by Ding et al. [9], investigating purely energy consumption of a variety of milling systems while machining. Azkarate et al. [10] concentrated on the development of a design support approach for the creation sustainable machine tools. Finding literature that covered the same or similar topics to this study was particularly difficult. This is primarily due to the focused nature of LCAs and the way which their results are very specific to the product or process the study has been applied to. Whilst studying previous LCAs it became very evident that there were only a limited number of studies looked at the life cycle of large scale machines and no obvious investigations of packaging systems. It was hoped that the results of this investigation will make the first steps into filling this gap and aid further studies into this, as of yet relatively unexplored area in environmental assessment.

\section{INVESTIGATION APPROACH}

This investigation takes the form of an abridged life cycle assessment focusing on the manufacturing and assembly stage of the machines life. The company provided parts lists and parts drawings for the machine and these were used to establish subassemblies through which environmental comparisons are made. The total embodied energy and carbon of each sub-assembly is calculated and their contribution to the whole machine established. The embodied energy and carbon was further broken down into material production and machine processes in order to establish where the major impacts are. The cheese packaging machine that is to be the subject of this study can be broken down into two major sub-sections, the In-Feeder and the Base, these are illustrated in Fig. 2a. Ideally, the embodied energy and carbon of both these sections would have been assessed. The In-feeder section is very specific to the cheese packaging machine; however, the base section is common to a number of the company's machines. All of the company machines involved in the packing and sealing process require the base sub-section to transform flat sheets of card into useful cartons. Variations in the size of cartons required does, however, create relative changes in the scale of each base section. It was decided that the conclusions that stood to be gained from a study of the base section would be the most useful to the company and could be scaled to make them relevant to a number of other machines. Base Subassemblies: There are over 2000 bespoke parts (not including standard parts; motors, fixing etc.) that are used to make up the base section of the packaging machine. Few useful conclusions would be made from a comparison of each individual part; as a result the base section has been divided up further into a number of subassemblies.

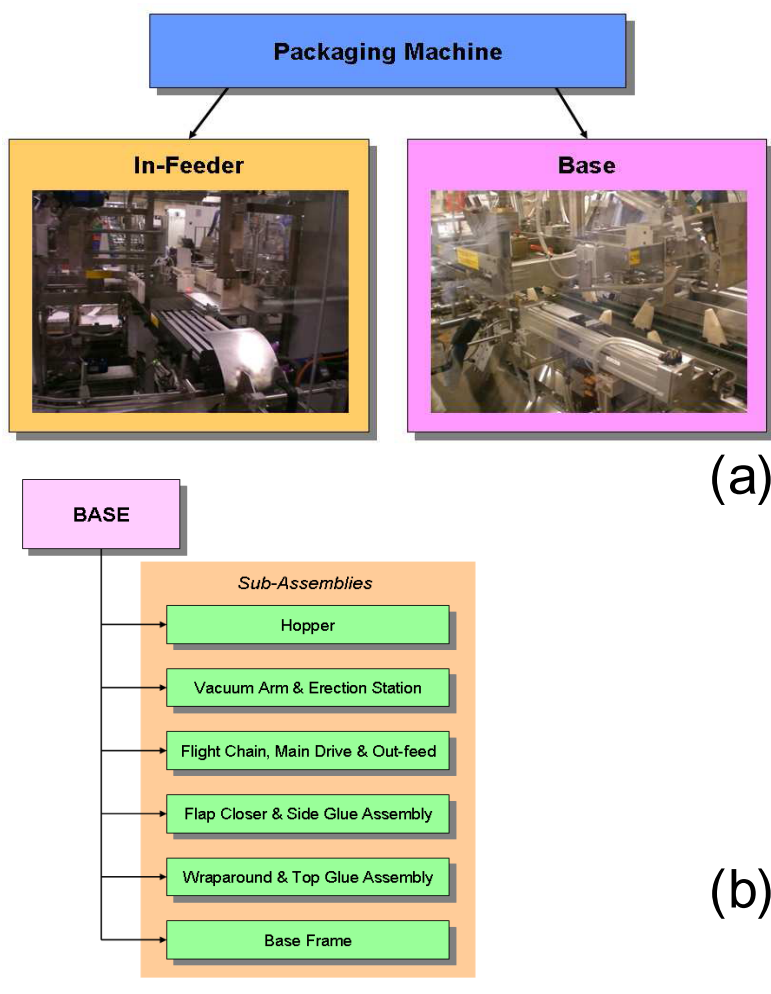

Fig. 2. Packaging Machine Sub-Sections

This final break down can be seen in Fig. $2 b$ this will 
identify which subassemblies have a particularly high environmental impact. The individual parts used to create the sub-assembly can then also be studied in order to indentify any energy and carbon "hot-spots". For the data collection (parts lists and drawings) detailed information was required for each of the parts, the company was able to provide parts lists for each of the sub-assemblies that were to be studied. However in order to analyze the embodied energy and carbon of the base details of the material used and weight of each part were also required. Many of the drawings were constructed in 2D format, and required the researchers to re-draw them in $3 \mathrm{D}$ to allow the investigations to be performed. The study was conducted in two parts: one researcher using Sima Pro7 [11] as the analysis tool (cf. Fig. 3a), the second researchers used Solidworks Sustainability as the main tool (cf. Fig. 3b). Embodied Energy and Carbon Data: Study "a" The Embodied Carbon and Energy (ICE) database produced by Hammond and Jones [12] at the University of Bath provides extensive information on typical values of embodied energy and carbon that can be expected from the production of materials. Study " $b$ " used the GaBi database [13] accessed in Solidworks "Sustainability".

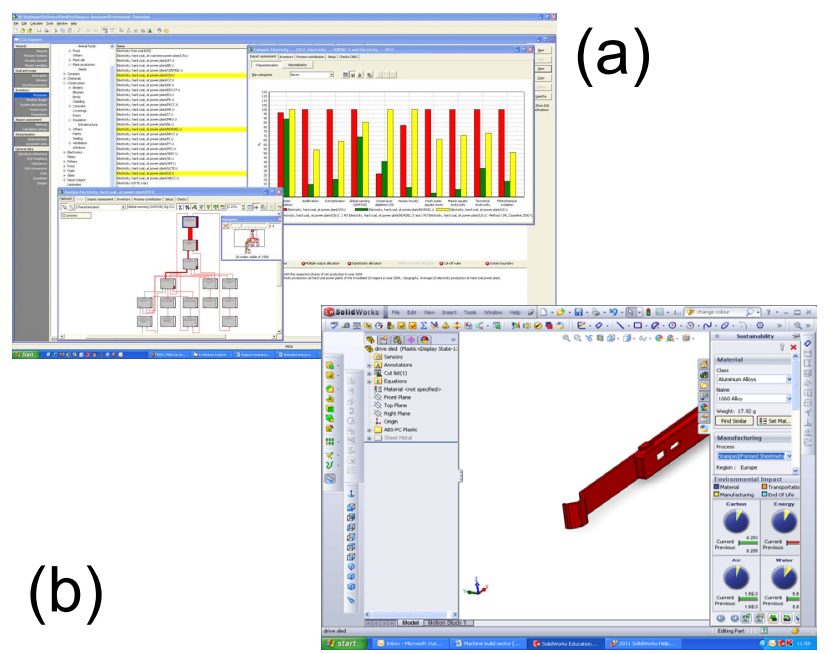

Fig. 3. Lifecycle analysis environments

In order to accurately analyze the assembly procedure it is necessary not only to look at the volume of material involved but also the machining processes used to shape each part. This study focuses on the assembly process at the company site; therefore, it was crucial to establish the machining requirements used to transform each standard part into a useful component. As a result, each of the part drawings provided by the company was once again studied, this time to establish the machining techniques that would have been used in order to create the piece. Along with the company, the manufacturing technical support teams at the Universities of Bath and Glamorgan were consulted in order to ensure that the machining processes used to fabricate each part were accurately identified as well as the time required of each procedure. It was established that almost all of the parts were produced using a combination of cutting the raw billet, milling, turning and welding.

The software packages were employed to gain access to the environmental databases and to perform cumulative energy and carbon analysis on each of the parts and the processes used to produce them. Cumulative Energy Demand
(CED) and Cumulative $\mathrm{CO} 2$ (CCO2) are forms of summing parameters by which all forms of energy use over a products life cycle are taken into consideration e.g. fossil fuels, nuclear, renewables etc. The impacts of these individual energy categories are then summed to find the complete impact of a product or process. By using these methods of analysis it can be assured that all forms of energy used in a process or to manufacture a product are accounted for in the impact assessment. These two methods can prove particularly useful as they are derived from the inventory analysis stage of a LCA and do not depend on assumptions made or uncertainties involved in impact assessment, the methods can also be used even if no impact assessment has been performed.

\section{AsSESSMENT RESUlts AND ANALYSIS}

From the data that has been gathered concerning each of the base subassemblies and the parts used to create them it has been possible to find specific values for the embodied energy and carbon of this section of the packaging machine. The total embodied energy of the base sub-section comes to $127162 \mathrm{MJ}$; in comparison it takes 259.6 MJ to boil one litre of water from room temperature. The total embodied carbon of the packaging machine is equal to $9175 \mathrm{kgCO} 2$ or $12.2 \mathrm{kgCO} 2 / \mathrm{kg}$. To put this value in perspective, in order to create one kg of plastic bags, six kg"s of $\mathrm{CO} 2$ is produced, this is less than half that produced in manufacturing the packaging machine. At this point the numbers obtained from this study may appear to be of little value or consequence in the machining and packaging world. However, it should be taken into account that a study of this sort has never before been undertaken and as a result there is no data available for comparison. This is the first environmental study of its kind on such a large scale packaging machine.
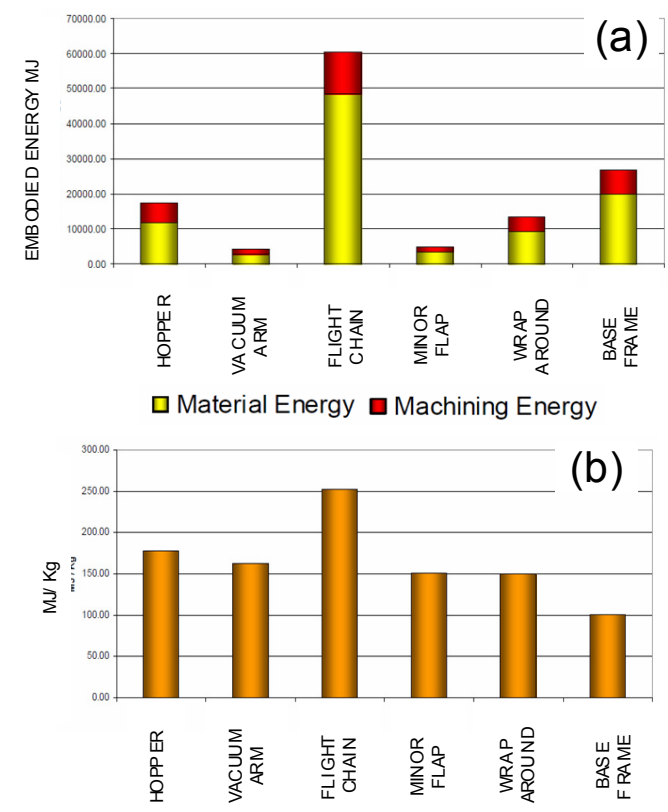

Fig. 4. a) embodied energy and; b) embodied energy per weight

Fig. 4a gives a comparison of the embodied energy involved in the construction of each of the six base sub-assemblies. The energy used is broken down into two 
elements; the embodied energy of the material and the cumulative energy produced from the machining processes. It can be seen that in each of the subassemblies the energy involved in producing material is far greater than that of the machining process; in most cases the embodied energy contributes to approximately $70 \%$ of the total energy. It can also be seen from Fig. 4a that the Flight Chain sub-assembly has the greatest embodied energy by quite some margin. Although Fig. 4a gives the true environmental impact of each of the sub-assemblies it can be argued that Fig. $4 \mathrm{~b}$ gives far more useful information. By dividing embodied energy by weight a much better comparison can be made of the sub-assemblies and areas of particularly poor performance identified. It can be seen that once again the Flight Chain sub-assembly has a notably higher impact than the other assemblies. The Sub-Assembly Weights were: Hopper $97.53 \mathrm{~kg}$, Vacuum Arm $25.57 \mathrm{~kg}$, Flight Chain $239.33 \mathrm{~kg}$, Minor Flap $33.12 \mathrm{~kg}$, Wraparound $89.54 \mathrm{~kg}$ and the Base Frame $266.21 \mathrm{~kg}$. A total weight for the unit of $751.30 \mathrm{~kg}$.
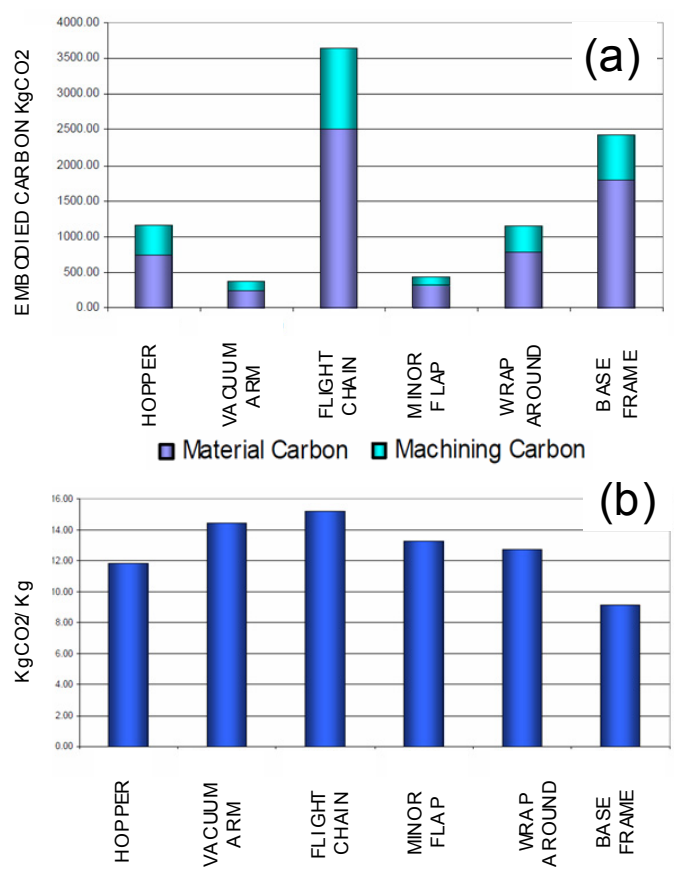

Fig. 5. a) embodied carbon; b) embodied carbon per weight

Fig. 5a illustrates that it is the Flight Chain sub-assembly that is the main contributor to the overall embodied carbon of the machine. The Base Frame also has a significant impact, whilst the Vacuum Arm and Minor Flap sub-sections provide a considerably smaller contribution than the other assemblies. However, once again, in order to gather a fairer comparison of the sub-assemblies the embodied carbon should be studied per kilogram. Fig. 5b shows that, unlike the results of the embodied energy per kilogram, there is not a large difference between the sub-assemblies. The Flight Chain is shown to have the highest impact; however, it is only marginally higher than the other assemblies. Excluding the Base Frame, there is only a difference of $3.3 \mathrm{kgCO}_{2} / \mathrm{kg}$ between the best and worst performing sub-assemblies.

\section{A. Design Impact of Individual Materials}

Analysis also shows that there are significant difference between the percentage embodied energy and carbon of the different sub-assemblies, and that the embodied energy of the
Flight Chain was particularly high. In order to gain a better understanding of why this is the contribution of individual materials has also been investigated. Fig. 6a and Fig. 6b present the percentage contribution that each material has on it sub-assembly, it is evident that, with the exception of the Flight Chain, the contribution of materials to each sub-assembly is pretty similar throughout. It is very evident that nylon has a significantly higher contribution to the embodied energy and carbon of the Flight Chain compared to all other sub-sections. It seems reasonable to conclude that it is the presence of such large quantities of nylon that have caused the embodied energy and carbon of the Flight Chain to be so high.

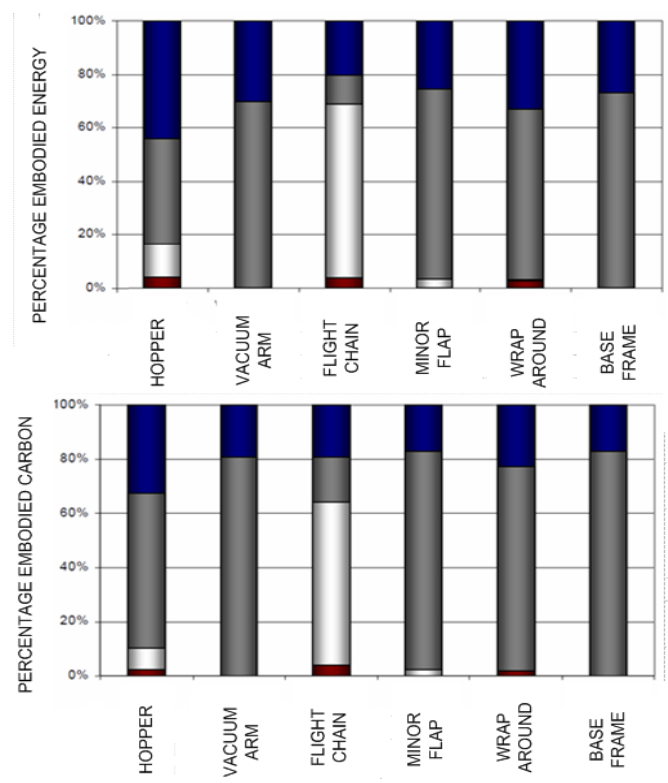

(b) Other $\mathbf{q}$ Nylon $\mathbf{\square}$ Steel $\boldsymbol{\square}$ Aluminium

Fig. 6. a) contribution of Materials to the Embodied Energy; b) carbon of each Sub-Assembly

\section{B. Material Production and Machining of Components}

As earlier mentioned, the embodied energy and carbon of the sub-assemblies has been calculated from two specific areas: the production of the material needed to produce each part and the machining processes needed to turn them into useful components. By breaking down the contribution of the six sub-assemblies into these two categories an additional insight into their performance can be gathered as well as further establishing where areas of poor performance have been generated. Fig. 7a and Fig. 7b show the percentage contribution of each sub-assembly in the material production process and the machining process respectively.

\section{Transportation}

Up until this point the transportation of parts to the company"s site has not been considered. This was because the company only gave very vague information about this aspect of the manufacturing However, for completeness, this section will briefly look at the cumulative energy produced through transportation. The company did not give specific details as to which parts came from which suppliers and precisely how far they had to travel. It did, however, mention that all parts are transported to their site by large vans from within a 20 mile radius. Solidworks sustainability does not have the capability to analyses such local transportation, so as 
a result SimaPro 7 was utilized to produce data for such a situation. Cumulative energy analysis was undertaken on a van capable of transporting a 3.5 tonne load. It was, however, found that in order to travel one mile the van uses $4.14 \times 10-3$ MJ of energy and hence over a 20 mile journey to the company $0.083 \mathrm{MJ}$ of energy are used. It is difficult, however, to include this data in the main analysis at present as without further information from the company is impossible to determine which parts are delivered individually and which are delivered together.

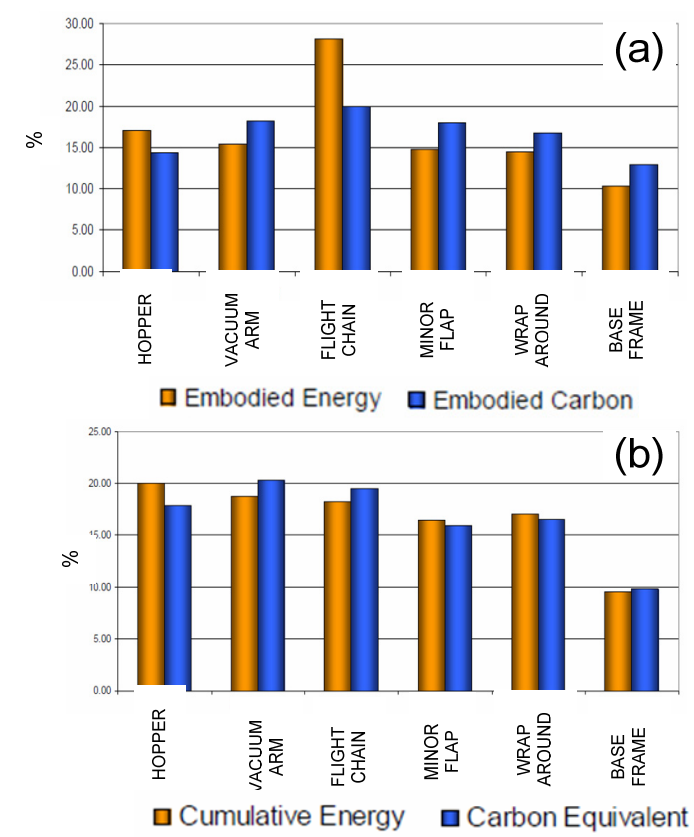

Fig. 7. a) Percentage Energy and Carbon per kilogram Produced via Material Production; b) Energy and Carbon per kilogram Produced via Machining

\section{Discussion: Outcomes Beneficial to the CoMpany}

Originally, this investigation was undertaken to give the company an idea of the environmental impact of their machine design. Although, an assessment of the whole machine has not been undertaken, this audit will go some way to providing the information the company wanted. In future if a customer is curious or concerned about the environmental impact of one of the packaging machines The company will be able to reassure them that environmental impact is an ongoing concern of the company"s and an environmental study of one of their machines has already been undertaken.

\section{A. Components Selected for Re-Design}

The poor environmental performance of several parts in the Flight Chain subassembly was investigated. The Chain Guides were the focus of this section. It has also been recognized that it is the main contributor to these high embodied energy and carbon counts due to the material production phase. As a result the data re-consulted and a number of parts selected for potential re-design. It was seen that there are ten parts labelled as "Chain Guides" and that these have a considerable contribution to the overall impact of the Flight Chain sub-assembly. These parts are very large, around two meters in length, which, obviously, increases their environmental impact, they are also made from nylon.
However, by comparing the properties of various materials potential improvements could be made. It is desirable to try and ensure that the weight of the part is not excessively increased by using a new material and that its strength is not reduced as this may compromise performance. Solidworks Sustainability has its own database to compare material properties, but the researcher user SimaPro had to use the CES EduPack computer program to select which materials would be suitable when the component in question was investigated further it was also found that one of its key requirements is to provide a wear resistant surface for the drive chain to run against. By using polyurethane the weight of the chain guide components would be marginally reduced and its embodied energy and carbon reduced by over 1000 $\mathrm{MJ}$ and over $60 \mathrm{CO} 2 \mathrm{~kg}$ respectively $(10.6 \%$ reduction in the embodied energy and a $7.5 \%$ decrease in the embodied carbon of the packaging machine). These changes would be possible without affecting the performance of the part or increasing the cost of the packaging machine. It was realized that there would be little point in suggesting a change in material to the company if this resulted in an increased cost, however, by switching the ten nylon components to polyurethane a potential saving of $£ 58.8$ could be made, with no implication to the existing machining process.

Although this study does provide the company with the energy and carbon audit they requested, it does not give the complete environmental impact of the machine. However, the company will now be able to show it has a keen interest in creating "greener machines" and quote to customers the embodied energy and carbon performance of its machine. Other environmental impacts of the machine such as contribution to ozone depletion have not, however, been looked at in this study. Due to this only being a partial LCA The company also only has knowledge of the impact of the manufacturing and assembly stages of their machine, the company will have to ensure further studies of the life cycle are undertaken in order to establish the impact of their machine over its The lack of comparative studies means that although The company now knows figures for the embodied energy and carbon for its machine they are unable to determine whether this is a good or poor performance in comparison to competitors" machines. It is hoped that this problem is remedied in the future as more studies of this nature are undertaken.

\section{LIMITATIONS AND IMPLICATIONS OF FINDINGS}

As with most investigations of this kind there were a number of different uncertainties and assumptions that have to be made during the course of the study. These uncertainties potentially limited the value and use of the final results. In this case, the limitations identified during the project have been split into two categories: data collection and LCA limitations. Also discussed in this section is a holistic evaluation of the two tools employed.

\section{A. Data Collection}

The data collection phases of this investigation for both studies "a" and "b" were a lengthy process in which every part of the company machine needed to be studied and 
calculations performed upon. With a process such as this, involving so many calculations it would seem naïve to assume that, despite the care taken, some rounding errors have not worked their way into a few of the results. Although the calculations were checked numerous times minor errors may still have been made. It should therefore be assumed there is some, small, degree of error in the results given. The information given on the material each part has been constructed from was taken from the parts drawings, however, this was limited. Importantly the proportion of recycled material used was unknown. The environmental impact of the parts will be significantly lower if constructed from recycled material as opposed to newly processed materials. The company could not provide information as to whether the materials used were recycled or not, as a result it was assumed that none of the parts were constructed from recycled material. In reality, there is most likely some proportion of recycled material used in the construction of the machine and hence its embodied energy and carbon will be less. It can therefore be concluded that the results of this environmental audit are for the worst case environmental performance of the packaging machine design.

Another potential issue with the results calculated is that the machining processes used to create each part were never witnessed. Experts in the field of manufacturing did provided assistance by looking at the parts drawings and establishing the probable methods of manufacture used in each case. However, in some cases several different processes could have been used to create the same part, some discrepancies may have been created due to these assumptions. The difference between the cumulative energy and carbon used in the machining processes considered is, however, very small, this will have hopefully kept the effect of any errors to a minimum. The reliability and accuracy of the Ecoinvent and Gabi databases used to gather information on manufacturing processes is also of concern. The database does provide comprehensive data on materials, manufacturing and transport, however, the constant developments made in these areas may have led to some of the information being out of date and obsolete. In addition to the parts investigated in this study there were also a number of small standard parts that were not analyzed. This was due to the lack of information available for such parts and the fact these parts were small enough that any environmental impact was predicted to be negligible. The manufacturer of these parts were contacted, but in most cases were either unable or unwilling to provide the required information. There is, however, a possibility that this prediction is not correct and that these parts do have a significant impact, this should be taken into account if the results of this assessment are used in further studies.

\section{B. LCA Limitations in this Investigation}

Importantly, the fact that these studies were not complete LCA, it could be argued that for a true understanding for the environmental impact of the packaging machine to be obtained a partial study does not suffice. In order to determine the complete environmental impact of the packaging machine this study needs to be continued and expanded, this will be mentioned in the following section detailing further work. A full LCA will also look at a wider range of effects that just embodied energy and carbon; the packaging could have a significant impact on many different areas, such as; global warming, acidification or eutrophication It should also be noted that a LCA of any kind, whether partial or complete is only a model and simplification of reality. Any results gathered from such a study will give an idealized idea of a product or processes impact but will not be able to predict there true impact. It is also very hard to judge whether or not certain processes should be included in a LCA and this can lead to some ambiguity in results.

\section{Comparison of Tools Employed}

Following on from the previous two sections there are also some more general observations in relation to the two approach tools:

- Currently it is common place for machine system designers to create their solutions directly within the CAD environment. Therefore tools such as "Sustainability" within Solidworks become a less intrusive option for the designer. It also has the capability to analyze a design in assembly form.

- The fact that some parts needed to be re-drawn for the analysis, made Solidworks Sustainability an effective tool for this investigation, as both researcher needed to use it.

- Although Solidworks Sustainability gives a report with multiple pie charts, SimaPro gave a far greater array of visualizations. These became very important when starting to compare between elements, also useful when presenting results to a third party.

- This investigation only gave a partial LCA where both software packages performed well. If this had been extended into a full LCA, then Solidworks Sustainability does not have the inherent functionality and a dedicated software package such as SimaPro would be required.

With the known limitations relating to the operating nature of machine design and build companies, the above important factors need to be considered when starting down the route of environmental analysis of packaging systems. It was found that whether the researchers used the "lightweight" package in Solidworks or used the full tool (SimaPro), they were both resource demanding in time to produce the outputs and to learn the system.

\section{Holistic Discussion}

The previous discussion formed discussion on the specifics and implications of the findings, this section will provide a holistic review of finding in relation to the initial objectives.

So, revisiting the first objective, the investigation and identification of a range of appropriate tools can be used to environmentally audit the design of a packaging system. Well, a range of approaches and methodologies had been identified, some reported in the review. But, in the end the safe option of a partial LCA was taken because from experience we knew some quantifiable findings would be produced and with a company involved we did not want to disappoint. An outcome we had hoped for as academics was, for the company to identify a knowledge or technique gap which could be exploited in further research, when all the 
company hoped for was a simplified and intuitive variant of existing approach. This lays more the domain of the tool suppliers to meet the demands of their clients.

The second specific objective was to formulate an environmental audit/ assessment of the packaging machine. As the paper reports this was done and as the discussion in the earlier section reported, it"s useful to the company as a comparator if they design and build new machines. But, on its own the finding are restricted, one may argue in the larger scale of design -limited

The final objective of the investigation was to evaluate the results of previous stages and produce an effective redesign solution by which the environmental impact could be reduced. This had been done and shown that materials had the greatest effect on the environmental impact of the design. Knowing this fact when the company enters the next design task, could the designers pay specific attention to the materials specified and thus the need to use LCA or other approaches be negated?

So in summary the project which was a feasibility study did not "throw up" the research questions from an academic perspective that had been hoped for. Whether expanding the study to a range of machine design companies in different economic areas would through up different results is likely to be the next step.

\section{CONCLUSIONS}

This paper has reported an abridged life cycle assessment of a packaging system for the manufacturing and assembly stages of its life cycle. The assessments have been split into several different aspects where the total embodied energy and carbon of the machine has been calculated, comparisons made between individual sub-assemblies, comparisons made between different materials and different machining processes, and finally components of comparatively poor environmental performance have been investigated and improved. These suggestions were made, as well as a comparison of material properties and, importantly, prices. This ensured that the company could realistically use the proposals put forward.

Via two separate studies it was shown that using a proprietary analysis system embedded in a CAD package, potentially offered a less intrusive option for environmental analysis within the design process, although such systems are functionally limited. So, for a comprehensive LCA to be conducted on a design packages such as SimaPro are necessary. As identified earlier most machine design companies are small in nature with limited resources, the requirement to learn and support another expensive software package is likely to limit its usage.

The results of this work may also appeal to a wider audience. As previously mentioned, an environmental study of this sort has never before been undertaken on a complex packaging machine. The results found can provide a point of reference and comparison for numerous other studies involving similar machines and packaging processes.

\section{ACKNOWLEDGMENT}

Special acknowledgments go to the manufacturing technical support teams at the Universities of Bath and Glamorgan.

\section{REFERENCES}

[1] R. Nowosielski, M. Spilka, and A. Kania, "A Methodology and tools of ecodesign," Journal of Achievements in Materials and Manufacturing Engineering, vol. 23, no. 1, pp. 91-94, 2007.

[2] S. G. Lee and X. Xu, "Design for the environment: life cycle assessment and sustainable packaging issues," International Journal of Environmental Technology and Management, vol. 5, no. 1, pp. 14-41, 2005 .

[3] J. Matthews, B. Hicks, G. Mullineux, J. Leslie, J. Goodwin, A. Ogg, and A. Campbell, "An empirical investigation into the influence of sealing crimp geometry and process settings on the seal integrity of traditional and biopolymer packaging materials," Packaging Technology and Science, DOI: 10.1002/pts.1991, 2013.

[4] B. Singh, J. Matthews, G. Mullineux, and A. J. Medland, "Product development in manufacturing SMES: Current state, challenges and relevant supportive techniques," in Proc. International Conference on Engineering Design (ICED'09), Stanford, CA, 2009.

[5] R. Pamminger, S. Gottschall, and W. Wimmer, "“LCA to go"-Environmental assessment of machine tools according to requirements of Small and Medium-sized Enterprises (SMEs)-development of the methodological concept," in Proceedings of the 37th International Matador Conference. Springer Verlag, 2012.

[6] A. Landfielda and V. Karrab, "Life cycle assessment of a rock crusher," Resources, Conservation and Recycling, vol 28, no. 3. pp 207-217, 2000 .

[7] S. R. Allen, G. P. Hammond, and M. C. McManus, "Energy analysis and environmental life cycle assessment of a micro-wind turbine," In Proceedings of the Institution of Mechanical Engineers, Part A: Journal of Power and Energy, vol. 222 (A7), pp. 669-684, 2008.

[8] C. I. Jones and M. C. McManus, "Life-cycle assessment of $11 \mathrm{kV}$ electrical overhead lines and underground cables," Journal of Cleaner Production, vol. 18, no.14, pp. 1464-1477, 2010

[9] L. Ding, X. L. Qui, G. Mullineux, and J. Matthews, "The development of the sustainable manufacturing process," Advanced Materials Research, vol. 118-120, pp. 767-774, 2010.

[10] A. Azkarate, I. Ricondo, A. Pérez, and P. Martínez, “An assessment method and design support system for designing sustainable machine tools," Journal of Engineering Design, vol. 22, no. 3, pp. 165-179. 2011.

[11] O. Goedkoop and O. Oele, "Introduction of LCA with SimaPro," PreConsultant Aersfoort, 2008.

[12] G. P. Hammond and C. I. Jones, "Embodied energy and carbon in construction materials," in Proceedings of the Institution of Civil Engineers - Energy, 2008, vol. 161, no.2, pp. 87-98.

[13] GaBi LCA database PE Consulting group. [Online]. Available: http://www.pe-international.com.

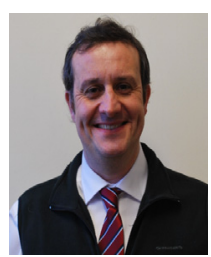

Jason Matthews is a senior lecturer in Engineering Design at the University of Glamorgan. He gained his $\mathrm{PhD}$ at the University of Bath. He has spent more than 15 years working in high volume manufacturing where he specialized in product and process automation. His current research interests deal with the creation of tools and methods to support the improved design and operation of high speed production machinery and manufacturing systems.

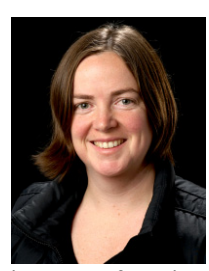

Marcelle McManus is a lecturer in the Department of Mechanical Engineering at the University of Bath. She has a particular interest in sustainability and life cycle impacts. Her research enables her to work with engineers to determine the environmental impact of different systems, with particular regard to renewable energy production. Marcelle's current research interests include investigating the life cycle environmental impact of various products and systems, primarily related to renewable energy and products.

Charlie Parr is a Master student of Engineering at the University of Bath.

Olaoluwa Araoye is a Master student of Engineering at the University of Glamorgan. 